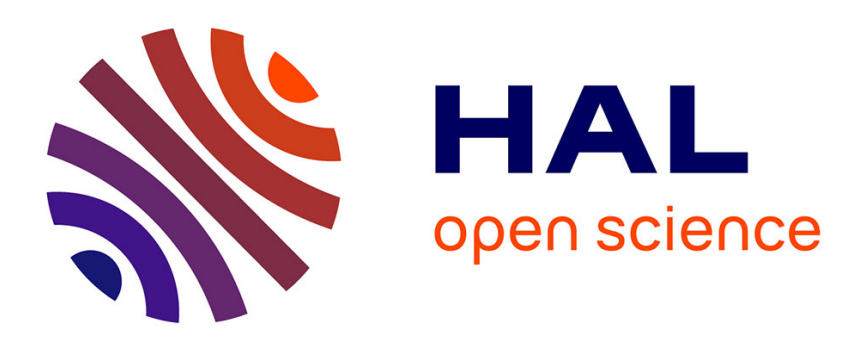

\title{
Stochastic modeling of consumer purchase behavior: I. Analytical Results
}

\author{
Albert C. Bemmaor
}

\section{To cite this version:}

Albert C. Bemmaor. Stochastic modeling of consumer purchase behavior: I. Analytical Results. 1981. hal-01277068

\section{HAL Id: hal-01277068 \\ https://essec.hal.science/hal-01277068}

Preprint submitted on 22 Feb 2016

HAL is a multi-disciplinary open access archive for the deposit and dissemination of scientific research documents, whether they are published or not. The documents may come from teaching and research institutions in France or abroad, or from public or private research centers.
L'archive ouverte pluridisciplinaire HAL, est destinée au dépôt et à la diffusion de documents scientifiques de niveau recherche, publiés ou non, émanant des établissements d'enseignement et de recherche français ou étrangers, des laboratoires publics ou privés. 


\section{CERESSEC}

Centre d'Etudes et de Recherche en Sciences Sociales, Economiques et Commerciales

STOCHASTIC MODELING OF CONSUMER PIRCHASE BEHAVICR:

I. ANALYTICAL RESULTS

Albert C. Bemmaor 
Comments welcome Not to be quoted

without written permission

STOCHASTIC MODELING OF CONSUMER PURCHASE BEHAVIOR:

I. ANALYTICAL RESULTS

Albert C. Bemmaor"

July 1981

Associate Professor, Ecole Supérieure des Sciences Economiques et Commerciales, Cergy Pontoise 95021, France. 
STOCHASTIC MODELING OF CONSUMER PURCHASE BEHAVIOR: I. ANALYTICAL RESULTS

This paper develops alternative brand purchase models. These models are based on distinct assumptions about the product class purchasing process over a fixed time-period. In each case, the brand choice process conditioned on a product purchase being made is assumed to be heterogeneous zero order. New analytical closedform results are derived. These results include various market statistics such as the brand penetration, the mean and variance of the brand purchase distribution and the aggregate brand purchase distribution itself. These theoretical expressions are based on the assumption of independence between brand choice probability and mean product purchase rate across the population. 
STOCHASTIC MODELING OF CONSUMER PURCHASE BEHAVIOR:

I. ANALYTICAL RESULTS

Albert C. Bemmaor

Over the past few years, much research has concentrated on the modeling of consumer purchase timing and brand choice behavior. The purchase timing process consists of the occurrences of product class purchases over a given time-period whereas the brand choice process deals with the prediction of choice conditioned on a purchase being made. Since Herniter's paper (1971), there has been a trend toward the separate modeling of both processes in a first step, and, in a second step, the building of a composite model of market behavior which predicts the aggregate brand purchase distribution over a fixed timeperiod (Zufryden 1977, Jeuland, Bass and Wright 1980). Researchers have altered either the purchase timing model or the brand choice model (or both) to derive analytically the resulting model of brand purchase. In every case, the assumption of independence between the brand choice probabilities and the average purchase rate of the product class has been made. This issue of independence has been empirically investigated over several product classes. Shoemaker et al. (1977) analyzed consumer panel data for three product categories (instant coffee, regular coffee and paper towels) and found that, in many cases, the hypothesis 
of independence was "a good first approximation". In Jeuland, Bass and Wright's study (1977) the simple correlations between relative frequencies of choice and mean purchase rate for catsup and cooking oil were below . 10 in absolute value for a total of thirty nine brands which led them to conclude: "this assumption is justified in the present case". The purpose of this paper is, firstly, to extend the body of purchase timing models so that the purchasing of additional product categories might be modeled, and, secondly, to derive closed-form expressions for various market statistics such as the brand penetration, the mean and variance of the number of brand purchases and the brand purchase distribution over a fixed time-period. This theoretical part will be followed by an empirical part which will focus on the fit of the alternative models to consumer panel data. In the first section, purchase incidence models are studied. These models describe the empirical distribution of the number of product class purchases over a given time-interval. The second section deals with the modeling of the distribution of the number of brand purchases over the same time period under the assumption of an heterogeneous multinomial distribution as a model of brand choice. The reason for solely considering this choice model is three-fold: 1) it has been shown to be fairly consistent with the evidence (Massy 1966, Dodson 1976, Bemmaor 1978, Jeuland, Bass and Wright 1980), 2) it fully describes choice behavior over the whole set of brands within a market, and 3) it leads to closed-form expressions for the various market statistics. The third section is a discussion on further analytical developments. 
Product class purchase model

The most simple model assumes that times between product class purchases for an individual consumer are independently distributed and follow an exponential distribution with mean $1 / \lambda$. Equivalently, the number of purchases over a fixed time interval is distributed Poisson with mean $\lambda$ (Rao 1973, p. 166). Assuming that the parameter $\lambda$ varies over the population according to a two-parameter gamma distribution, we find that the number of purchases follows a Negative Binomial Distribution (NBD) over the population. Ehrenberg (1959) applied this distribution to a marketing situation. Noting that, for such product classes as washing-up liquids, razor blades, dentifrice and toilet soap, consumers tend to buy more regularly than Poisson, Chatfield and Goodhardt (1973) discussed the use of the Condensed-2. Poisson for which the variability ratio (variance/mean) varies between 1 and 0.5 depending on the individual mean purchase rate. Interpurchase times are then distributed Erlang-2 (instead of exponential as in the Poisson process). Letting the mean of the Condensed-2 Poisson distribution vary over the population according to a gamma distribution, Chatfield and Goodhardt derived the Condensed-2 Negative Binomial Distribution as the aggregate distribution of the number of purchases. The probability density function of the Erlang-n model with scale parameter $\lambda$ is

$$
f(t \mid n, \lambda)=\frac{\lambda^{n}}{\Gamma(n)} t^{n-1} e^{-\lambda t}, . \quad \lambda>0, n=1,2,3, \ldots, \text { and } t>0 .
$$

Considering an alternative distribution to the Erlang-n model, Banerjee and Bhattacharyya (1976) suggested the use of the two- 
parameter Inverse Gaussian (IG) distribution whose probability density function is

$$
f(t \mid \psi, \phi)=(\phi / 2 \pi)^{\frac{1}{2}} t^{-\frac{3}{2}} \exp \left\{-\phi t(\psi-1 / t)^{2} / 2\right\}, \psi>0, \phi>0 \text { and } t>0
$$

This distribution has an advantage over the Erlang-n distribution in that it allows for a bivariate compounding over the population. All of these modeling efforts for interpurchase times might be considered as special cases of a general class of probability distributions: the three-parameter Generalized Inverse Gaussian distribution (GIG). Its probability density function is given by (Barndorff-Nielsen, Blaesild and Halgreen 1978):

$$
f(t \mid n, \zeta, \tau)=\frac{(\tau / \zeta)^{\eta / 2}}{2 k_{\eta}[V(\zeta \tau)]} t^{\eta-1} \exp \left\{-\frac{1}{2}\left(\zeta t^{-1}+\tau t\right)\right\}, t>0
$$

where the variation domain of the parameter $(\eta, \zeta, \tau)$ is such that $\zeta>0, \tau>0$ for $n<0, \zeta>0, \tau>0$ for $n=0$ and $\zeta \geqslant 0, \tau>0$ for $n>0$ and $k_{n}[\cdot]$ is the modified Bessel function of the third kind with index $\eta$. It can be shown that the negative exponential function $\xi(\lambda)$ and the Erlang-2 distribution with parameter $\lambda$ are equivalent to the $\operatorname{GIG}(1,0,2 \lambda)$ and to the GIG $(2,0,2 \lambda)$ respectively. The Inverse Gaussian distribution with parameter $(\psi, \phi)$ is equivalent to the $\operatorname{GIG}\left(1 / 2, d_{0}^{2}, \mu^{2}\right)$ with $\psi=\mu / d_{0}$ and and $\phi=d_{0}^{2}$ (see Appendix A) .

Individual consumer purchasing behavior: the Condensed-3 Poisson distribution

The Erlang-n model is characterized by a coefficient of variation equal to $1 / \sqrt{n}$. To investigate the magnitude of the order $\mathbf{n}$ of the Erlang 
model, empirical analyses of the relative frequencies of the coefficients of variation (standard deviation/mean) of interpurchase times distributions were made. The results showed that for a product class such as regular coffee, the median was closer to $1 / \sqrt{ } 3$ than to $1 / \sqrt{ } 2$ (as implied by an Erlang-2 interpurchase time distribution) over the population. In her doctoral research, Cynthia Fraser found a similar result for the whole coffee market (instant coffee plus regular coffee). These results seem to indicate that the Erlang-3 model would provide a better description of the distribution of interpurchase times than the Erlang-2 model. The number of purchases over a fixed time-period are then distributed as Condensed-3 Poisson instead of Condensed-2 Poisson. Haight (1967, p. 57) provides the general analytical form for the Condensed $-n(n=1,2,3,4, \ldots)$ Poisson distribution. ${ }^{2}$ For $n=3$, the distribution function is

$$
\begin{aligned}
P_{C 3}(0 \mid \lambda) & =P_{p}(0 \mid \lambda)+\frac{2}{3} P_{p}(1 \mid \lambda)+\frac{1}{3} P_{p}(2 \mid \lambda) \\
P_{C 3}(k \mid \lambda) & =\frac{1}{3} P_{p}(3 k-2 \mid \lambda)+\frac{2}{3} P_{p}(3 k-1 \mid \lambda)+P_{p}(3 k \mid \lambda) \\
& +\frac{2}{3} P_{p}(3 k+1 \mid \lambda)+\frac{1}{3} P_{p}(3 k+2 \mid \lambda), k=1,2,3, \ldots
\end{aligned}
$$

where

$$
P_{p}(k \mid \lambda)=e^{-\lambda} \frac{\lambda^{k}}{k !} .
$$

The mean and variance are $\lambda / 3$ and $\lambda / 9+4 / 27\left[1-e^{-3 / 2 \lambda} \cos \left(\frac{\sqrt{3}}{2} \lambda\right)\right]$ respectively (Appendix $B$ ). The variability ratio goes to $\frac{1}{3}$ as $\lambda$ tends to infinity. The correlation between consecutive purchases is negative for $\lambda$ positive and attains its maximum in absolute value $\left(p_{12}=-.226\right)$ when $\lambda \approx 1.276$ (Appendix $C$ ). By comparison, for the Condensed-2 Poisson 
distribution, the maximum correlation $\left(p_{12}=-.013\right)$ is reached when $\lambda \approx 0.81$ (Chatfield and Goodhardt 1973). The correlation between consecutive purchases increases in magnitude as the order $\mathrm{n}$ of the Erlang model increases. Inventory behavior might be allowed for by increasing the order. This issue is also evidenced through the study of the hazard function as expressed by

$$
z(t)=\frac{f(t)}{1-F(t)}
$$

where $f(t)$ is the probability density function of $t$ and $F(t)$ is the cumulative distribution function (Cox and Lewis 1966, p. 135). This function represents the likelihood of a purchase occurring given that no purchase has yet occurred. The hazard function for the Erlang-n distribution with scale parameter $\sigma$ is $z(t)=(t / \sigma)^{n-1} /\{\sigma(n-1) !$ $\left.\left[\sum_{i=0}^{n-1}(t / \sigma)^{i} /(i !)\right]\right\}$ (Hastings and Peacock 1974, p.54) $)^{3}$. For the Inverse Gaussian distribution, it was computed through the use of a numerical integration subroutine (IMSL 1979b). The hazard functions are shown in Figure 1.A and 1.B. As time passes, the conditional likelihood of making a purchase increases monotonically for the Erlang distribution whereas it decreases after reaching a peak for the Inverse Gaussian distribution. The rate of increase of the hazard function is lower for the higher order Erlang model which reflects the strength of the inventory effect on time to repurchase.

Model of aggregate purchasing behavior: the Condersed-3 Negative Binomial Distribution

Assume that the mean $\lambda / 3$ of the Condensed-3 Poisson follows a two-parameter gamma distribution with shape parameter $r$ and scale parameter $\sigma$ over the population. 


$$
\mathrm{dF}\left(\frac{\lambda}{3} \mid r, \sigma\right)=\frac{1}{\sigma^{r} \Gamma(r)}\left(\frac{\lambda}{3}\right)^{r-1} e^{-\frac{\lambda}{3 \sigma}} \mathrm{d}\left(\frac{\lambda}{3}\right) .
$$

It follows that the distribution of $\lambda$ is gamm $(r, 3 \sigma)$, i.e.,

$$
\begin{aligned}
d F\left(\frac{\lambda}{3} \mid r, \sigma\right) & =\frac{1}{(3 \sigma)^{r} \Gamma(r)} \lambda^{r-1} e^{-\frac{\lambda}{3 \sigma}} d \lambda \\
& =f(\lambda \mid r, 3 \sigma) d \lambda
\end{aligned}
$$

The distribution of the number of purchases (2), unconditioned on $\lambda$, is given by

$$
\begin{aligned}
& P_{\mathrm{CN} 3}(0)=\int_{0}^{+\infty} P_{\mathrm{C} 3}(0 \mid \lambda) \mathrm{f}(\lambda \mid r, 3 \sigma) \mathrm{d} \lambda \\
& \mathrm{P}_{\mathrm{CN} 3}(\mathrm{k})=\int_{0}^{+\infty} \mathrm{P}_{\mathrm{C} 3}(\mathrm{k} \mid \lambda) \mathrm{f}(\lambda \mid r, 3 \sigma) \mathrm{d} \lambda, \mathrm{k}=1,2,3, \ldots
\end{aligned}
$$

Replacing $\mathrm{P}_{\mathrm{C} 3}(\mathrm{O} \mid \lambda)$ and $\mathrm{P}_{\mathrm{C} 3}(\mathrm{k} \mid \lambda)$ in $(3)$ by $(2)$, we obtain

$$
\begin{aligned}
P_{C N 3}(0) & =P_{N}(0)+\frac{2}{3} P_{N}(1)+\frac{1}{3} P_{N}(2) \\
P_{C N 3}(k) & =\frac{1}{3} P_{N}(3 k-2)+\frac{2}{3} P_{N}(3 k-1)+P_{N}(3 k) \\
& +\frac{2}{3} P_{N}(3 k+1)+\frac{1}{3} P_{N}(3 k+2), \quad k=1,2,3, \ldots
\end{aligned}
$$

where $\mathrm{P}_{\mathbb{N}}(k)$ is the $\operatorname{NBD}(r, 3 \sigma)$ 


$$
\mathrm{P}_{\mathrm{N}}(\mathrm{k})=\frac{\Gamma(k+r)}{\Gamma(r) k !}\left(\frac{3 \sigma}{1+3 \sigma}\right)^{\mathrm{k}}(1+3 \sigma)^{-r} .
$$

This distribution is called the Condensed-3 Negative Binomial

Distribution. Its mean equals one-third the mean of the $\operatorname{NBD}(r, 3 \sigma)$, $\sigma r$, and its variance is $\sigma \mathrm{r}(\sigma+1 / 3)+4 / 27\left\{1-\cos (\mathrm{r} \delta) /\left(1+9 \sigma+27 \sigma^{2}\right)^{\mathrm{r} / 2}\right\}$ where $\sin \delta=\sqrt{ } 3 / q, \cos \delta=1 / q(3 / 2+1 / 3 \sigma)$ and $q=\left[(3 / 2+1 / 3 \sigma)^{2}+3 / 4\right]^{1 / 2}$ (Appendix D). The shape of this distribution is compared to that of the Condensed-2 NBD and of the NBD for various values of $r$ and a fixed scale parameter $\sigma$ in Figure 2. Note that the proportion of nonbuyers decreases as the order of the Erlang distribution increases. These distributions become more and more humped with an increase in the order.

\section{Brand purchase model}

The purpose of this section is to derive the brand purchase distribution over a fixed time-period under various assumptions about the product purchase model. Zufryden (1977) considered the linear learning model as a brand choice model, conditional upon a product purchase being made. This model describes choice behavior in a twobrand market only. We will consider a multi-brand market and we will assume that brand choice probabilities vary among consumers. The model is based upon three distinct assumptions: 1) independence between consecutive choice occasions, 2) consumer's vector of probabilities of choosing among $(N+1)$ brands $\left[\theta_{1}, \ldots, \theta_{i}, \ldots, \theta_{N}\right]$ is constant over time, and 3 ) the vector of probabilities varies over the population according to a Dirichlet distribution whose probability density function is 


$$
f\left(\theta_{1}, \ldots, \theta_{N}\right)=\left[\prod_{i=1}^{N} \theta_{i}^{a_{i}-1} / \Gamma\left(a_{i}\right)\right]\left(1-\sum_{i=1}^{N} \theta_{i}\right)^{a^{N+1}-1} \Gamma(c)
$$

where $\left[a_{1}, \ldots, a_{\mathrm{N}+1}\right]$ is the vector of parameters of the distribution, $\Gamma(\cdot)$ is the gamma function, $a_{i}>0$ for $a 11 i$ and $\sum_{i=1}^{N+1} a_{i}=c$. Mosimann (1962) studied the properties of this distribution and applied it to biology. Chatfield and Goodhardt (1975), Bass, Jeuland and Wright (1976) and Kalwani and Morrison (1977) discussed its use in a brand choice context. The marginal distribution of each component $\theta_{i}$ is a beta distribution with parameter $\left(a_{i}, b_{i}=c-a_{i}\right)$. The compound multinomial distribution gives the theoretical distribution of the vector of brand purchases over the population, conditioned on a given number of purchases of the product class. It is useful to derive the unconditional distribution of the number of brand purchases over a fixed time-period by making alternative assumptions about the product purchase distribution for individual constmers. The following analytical results are based upon the three following assumptions:

A1. Independence between brand choice probability $\theta_{i}$ and average purchase rate of the product class $\lambda / n(n=1,2,3, \ldots)$ over the population.

A2. $\theta_{i}$ follows a beta distribution with parameter $\left(a_{i}, b_{i}=c-a_{i}\right)$.

A3. The mean of the Condensed-n Poisson $(n=1,2,3, \ldots) \lambda / n$ is distributed gamma with parameter $(r, \sigma)$. It follows that $\lambda$ is distributed gamna with parameter $(r, n \sigma)$.

\section{Poisson assumption for consumer product purchases}

Assume that the number of purchases $x$ of Brand $i$ over a fixed number of product purchases $k$ is binomial with parameter $\theta_{i}$, 


$$
P\left(x \mid k, \theta_{i}\right)=\left(\begin{array}{l}
k \\
x
\end{array}\right) \theta_{i}^{x}\left(1-\theta_{i}\right)^{k-x} \quad 0<\theta_{i}<1, x=0,1,2, \ldots, k .
$$

Let $P(k \mid \lambda)$ be the distribution of $k$ with parameter $\lambda$ over a given time-period. The distribution of $x$, unconditioned on $k$, is given by

$$
P\left(x \mid \theta_{i}, \lambda\right)=\sum_{k=0}^{\infty} P\left(x \mid k, \theta_{i}\right) P(k \mid \lambda)
$$

If $P(k \mid \lambda)$ is a Poisson distribution, $P\left(x \mid \theta_{i}, \lambda\right)$ is Poisson with parameter $\lambda \theta_{i}$ (Feller 1968, Eq.2.11 in Ch.12)

$$
P\left(x \mid \theta_{i}, \lambda\right)=e^{-\lambda \theta_{i}} \frac{\left(\lambda \theta_{i}\right)^{x}}{x !}
$$

The mean and variance of $(6)$ are both equal to $\lambda \theta_{i}$. Under the assumptions $\mathrm{A} 1, \mathrm{~A} 2$, and $\mathrm{A} 3$, the distribution of $\mathrm{x}$, unconditioned on $\theta_{i}$ and $\lambda$, is given by (see E.2)

$$
P(x)=\frac{\Gamma(c) \sigma^{x} \Gamma(x+r) \Gamma\left(x+a_{i}\right)}{\Gamma\left(a_{i}\right) \Gamma(r) x ! \Gamma(x+c)} F_{D}^{(1)}\left(x+r, x+a_{i} ; x+c ;-\sigma\right)
$$

where $\mathrm{F}_{\mathrm{D}}^{(1)}\left(\mathrm{m}_{0}, \mathrm{~s}_{1} ; \mathrm{u} ; \mathrm{z}_{1}\right)=\frac{\Gamma(\mathrm{u})}{\Gamma\left(\mathrm{m}_{0}\right) \Gamma\left(\mathrm{u}-\mathrm{m}_{0}\right)} \int_{0}^{1} \mathrm{w}^{\mathrm{m}_{0}^{-1}}(1-\mathrm{w})^{\mathrm{u}-\mathrm{m}_{0}-1}\left(1-\mathrm{z}_{1} \mathrm{w}^{-\mathrm{s}_{1}} \mathrm{dw}\right.$ is the integral representation of a Lauricella series with $u>u-m_{0}>0$ and $|z|<1$ for absolute convergence. For $x=0$, we find

$$
P(0)=F_{D}^{(1)}\left(r, a_{i} ; c ;-\sigma\right)
$$


To find the penetration of the brand over $I$ basic time-periods, we replace $\sigma$ by $\sigma \mathrm{T}$ in $(\mathrm{E} .3)$ and compute $1-\mathrm{P}(\mathrm{O} \mid \mathrm{T})$. The mean and variance of this distribution are $r \sigma a_{i} / c$ and $r \sigma a_{i} / c\left[\sigma /(c+1)\left(r b_{i} / c+a_{i}+1\right)+1\right]$ respectively (see G.3 and G.4).

\section{Condensed-2 Poisson assumption for consumer product purchases}

Assume that $P(k \mid \lambda)$ in $(5)$ is Condensed-2 Poisson as given by Chatfield and Goodhardt (1973),

$$
\begin{aligned}
& P_{C 2}(0 \mid \lambda)=P_{p}(0 \mid \lambda)+\frac{1}{2} P_{p}(1 \mid \lambda) \\
& P_{C 2}(k \mid \lambda)=\frac{1}{2} P_{p}(2 k-1 \mid \lambda)+P_{p}(2 k \mid \lambda)+\frac{1}{2} P_{p}(2 k+1 \mid \lambda) k=1,2,3
\end{aligned}
$$

with

$$
P_{p}(k \mid \lambda)=e^{-\lambda} \frac{\lambda^{k}}{k !}
$$

The mean and variance of $P\left(x \mid \theta_{i}, \lambda\right)$ are $\lambda \theta_{i} / 2$ and $\theta_{i} / 2\left[\lambda-\theta_{i} / 2\left(\lambda-e^{-\lambda}\right.\right.$ $\sinh \lambda$ )] respectively (see $G .5$ and $G .6$ ). Note that the conditional distribution of $x$ is not Condensed-2 Poisson. With $\xi=\left(1-\theta_{i}\right)^{\frac{1}{2}}$ the probability that a consumer with parameter $\theta_{i}$ and $\lambda$ makes no purchase is (see F.2)

$$
P\left(x=0 \mid \theta_{i}, \lambda\right)=e^{-\lambda}\left[\frac{1}{2} \xi \sinh (\xi \lambda)+\cosh (\xi \lambda)+\frac{1}{2} \xi^{-1} \sinh (\xi \lambda)\right] .
$$


Under the assumptions $A 1, A 2$ and $A 3$, the unconditional probability of no purchase is given in (F.3). The mean and variance of the brand purchase distribution over the population are $r \sigma a_{i} / c$ and $r \sigma a_{i} /$ $c\left[\sigma /(c+1)\left(r b_{i} / c+a_{i}+1\right)+1-\left(a_{i}+1\right) / 2(c+1)\right]+1 / 8 a_{i}\left(a_{i}+1\right) / c(c+1)\left[1-(1+4 \sigma)^{-r}\right]$ (see G.7 and G.8).

\section{Condensed-3 Poisson assumption for eonsumer product purchases}

Assume that $P(k \mid \lambda)$ in $(5)$ is Condensed-3 Poisson as shown in (2). The probability that a consumer with given average product purchase rate $\lambda / 3$ and brand choice probability $\theta_{i}$ makes no purchase is presented in (F.4). The mean and variance of the distribution of this consumer brand purchases are $\lambda \theta_{i} / 3$ and $\theta_{i} / 3\left\{2 \theta_{i} / 3\left[2 / 3\left(1-e^{-\frac{3}{2} \lambda} \cos \left(\frac{\sqrt{3}}{2} \lambda\right)\right)-\lambda\right]+\lambda\right\}$ respectively (see G.9 and G.10). Note again that this distribution is not Condensed-3 Poisson. Under the assumptions A1, A2 and A3, the proportion of non-buyers over the population is given in (F.6). The analytical expression for this proportion is fairly complex but it is computable through the use of numerical integration methods. The mean and variance of the brand purchase distribution over the population are $r \sigma a_{i} / c$ and $r \sigma a_{i} / c\left[\sigma /(c+1)\left(r b_{i} / c+a_{i}+1\right)+1-2 / 3\left(a_{i}+1\right) /\right.$ $(c+1)+4 / 27 a_{i}\left(a_{i}+1\right) / c(c+1)\left[1-\cos (r \delta) /\left(1+9 \sigma+27 \sigma^{2}\right)^{r / 2}\right]$ with $\sin \delta=\sqrt{ } 3 / 2 q$, $\cos \delta=1 / q(3 / 2+1 / 3 \sigma)$ and $q=1 / 3 \sigma\left(1+9 \sigma+27 \sigma^{2}\right)^{1 / 2}$ (see $G .11$ and $G .12$ ). 


\section{Discussion}

Alternative models of brand purchase over a fixed time-period have been developped. These models need to be tested and compared over various sets of empirical data. Part II will deal with this model testing issue. The purchase incidence models for product class purchases as well as the brand choice model considered here are empirically based. This approach to modeling consumer purchasing behavior is complete, although parsimonious. It describes the product purchasing process and the brand choice process with a reasonable number of parameters. In total, the aggregate model for the brand purchase distribution includes four parameters. The issue of the Dirichlet estimaticn has been dealt with at length by Bass, Jeuland and Wright (1976). For the estimation of the NBD, Ehrenberg (1959) advocates the use of the product class penetration (proportion of buyers who bought the product class at least once over a fixed time-period) and of the mean product purchase rate over the population. Various extensions of this modeling effort might be carried out. A particularly useful work would consist of modeling the whole consumer purchasing behavior by including store choice as well as product class choice within a similar framework. This approach seems promising to describe market behavior under stationary conditions. Other research developments might involve the inclusion of marketing variables as determinants of brand choice and product purchase over a fixed time-period. Some recent efforts have analyzed the effects on brand choice (Jones and Zufryden, 1980). More extensive work along these lines is currently needed. 
FOOTNOTES

Private conversation in Cynthia Fraser's office at Columbia University for which the author is most grateful. Cynthia Fraser will report her findings in a forthcoming paper.

2 For $n=1$, we obtain the common Poisson distribution

The hazard function of the Erlang distribution in Hastings and Peacock (1974) includes a typographical error.

The analytical expression of the distribution of brand purchases for a consumer with given parameter $\theta_{i}$ and $\lambda, P\left(x \mid \theta_{i}, \lambda\right)$, has not been derived due to the complexity of the series expansions. 

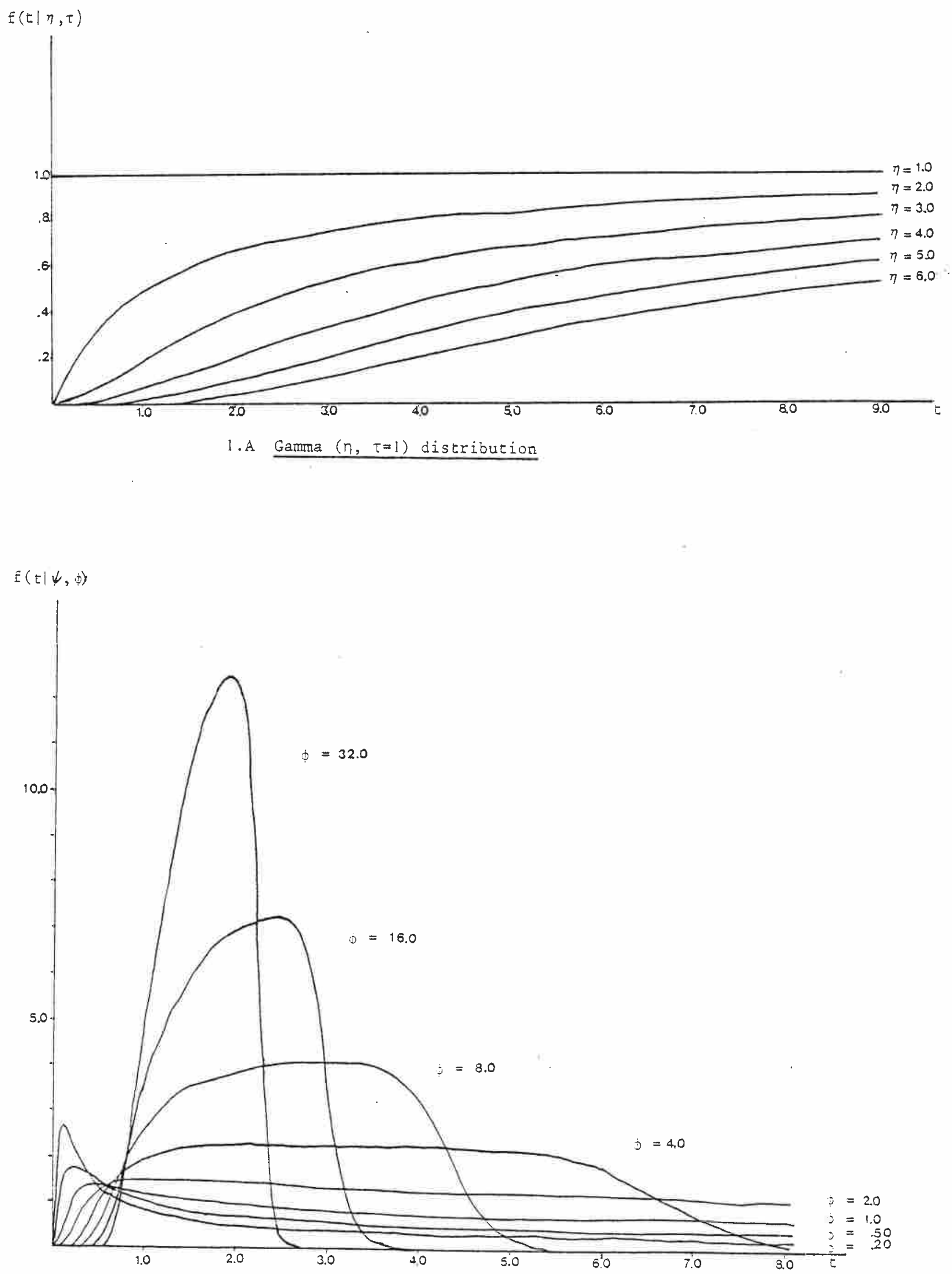

I. Inverse Gaussian $(j=1.0)$ distribution 

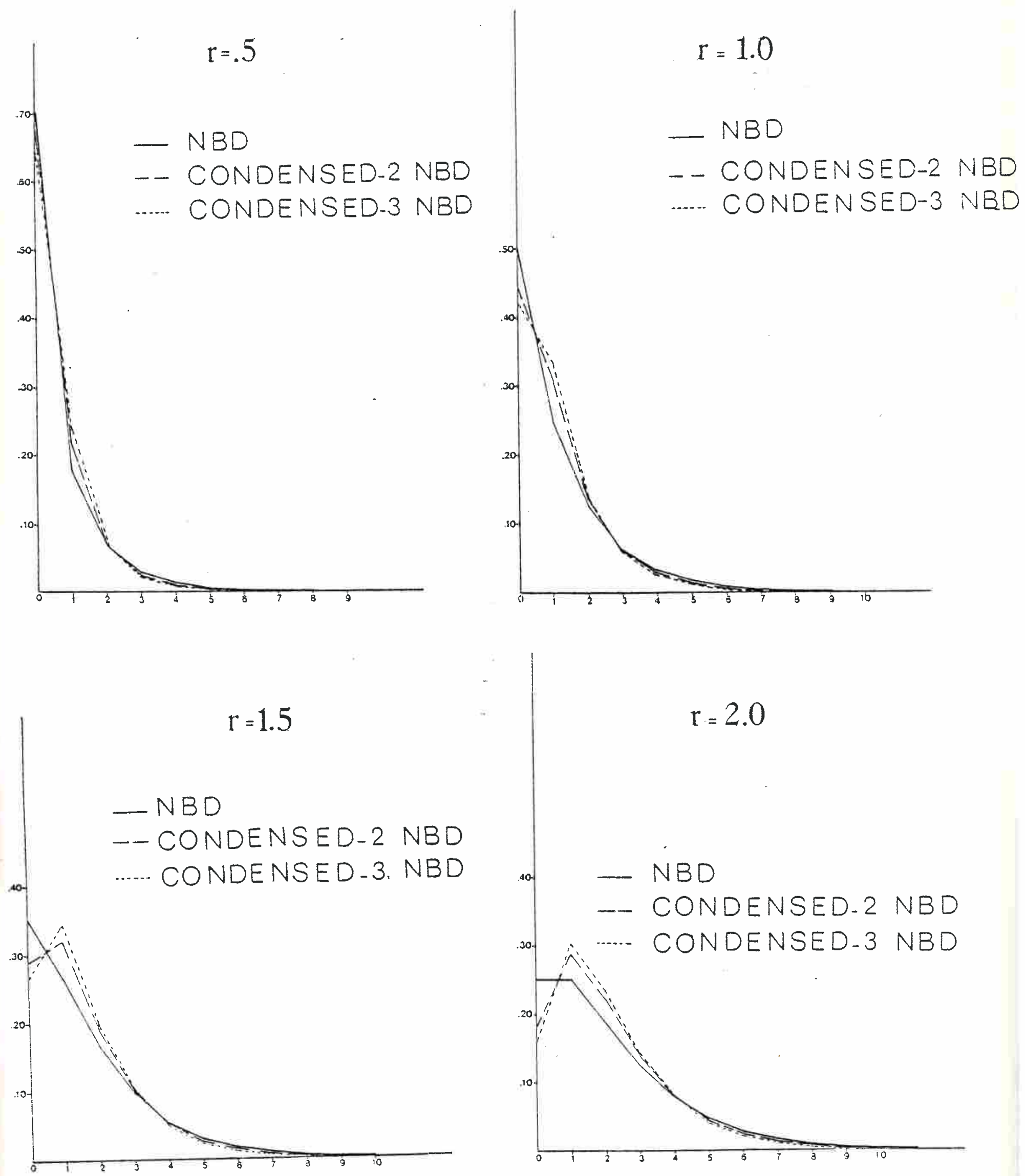
APPENDIX A

\begin{abstract}
Relationship between the Gamma Distribution and the Inverse Gaussian Distribution
\end{abstract}

Consider the probability density function (1). It can be shown that a gamma distribution with parameter $(n, \tau / 2)$ is equivalent to a $\operatorname{GIG}(\eta, 0, \tau)$.

Proof: We know that $k_{n}(y) \sim \Gamma(n) 2^{n-1} y^{-n}$ for $y \rightarrow 0$. Therefore $K_{n}[\sqrt{ }(\zeta \tau)] \sim \Gamma(n) 2^{n-1}(\zeta \tau)^{-n / 2}$. Hence (1) becomes $\left\{\tau^{n} /\left[\Gamma(n) 2^{n}\right]\right\} t^{n-1} e^{-\frac{\tau}{2} t}$ which is the gamma distribution with parameter $(n, \tau / 2)$. The negative exponential function $\mathscr{\ell}(\lambda)$ is equivalent to the GIG $(1,0,2 \lambda)$, the Erlang-2 distribution with parameter $\lambda$ is equivalent to the $\operatorname{GIG}(2,0,2 \lambda)$, and so on. Also, it can be shown that the $I G(\psi, \phi)$ is equivalent to the $\operatorname{GIG}\left(1 / 2 \mathrm{~d}_{0}^{2}, \mu^{2}\right)$. with $\psi=\mu / \mathrm{d}_{0}$ and $\phi=\mathrm{d}_{0}^{2}$.

Proof: We know that $K_{n}(y) \sim\left(\frac{1}{2} \pi / y\right)^{\frac{1}{2}} e^{-y}$ for $y \rightarrow \infty$. Therefore for $d_{0} \mu$ large, $\left.k_{-\frac{1}{2}}\left(d_{0} \mu\right) \sim\left[1 / 2 \pi / d_{0} \mu\right)\right]^{2} e^{-d_{0} \mu}$. Hence (1) becomes $\left(d_{0}^{2} / 2 \pi\right)^{\frac{1}{2}} t^{-\frac{3}{2}} \exp \left\{-1 / 2 d_{0}^{2} t\left(\mu / d_{0}-1 / t\right)^{2}\right\}$ which is $I G\left(\psi=\mu / d_{0}, \phi=d_{0}^{2}\right)$ 
APPENDIX B

Variance of the Condensed-3 Poisson Distribution

Consider the Condensed-3 Poisson distribution (2). The second moment about the origin for a random variable $k$ which has the Condensed-3 Poisson distribution is given by

$$
\begin{aligned}
E\left[k^{2} \mid \lambda\right] & =\frac{1}{3} \sum_{k=1}^{\infty} k^{2} P_{p}(3 k-2)+\frac{2}{3} \sum_{k=1}^{\infty} k^{2} P_{p}(3 k-1)+\sum_{k=1}^{\infty} k^{2} P_{p}(3 k) \\
& +\frac{2}{3} \sum_{k=1}^{\infty} k^{2} P_{p}(3 k+1)+\frac{1}{3} \sum_{k=1}^{\infty} k^{2} P_{p}(3 k+2) \\
& =\frac{1}{3} \frac{1}{9} \sum_{k=1}^{\infty}(3 k-2)^{2} P_{p}(3 k-2)+\frac{1}{3} \frac{1}{9} \sum_{k=1}^{\infty}(12 k-4) P_{p}(3 k-2) \\
& +\frac{2}{3} \frac{1}{9} \sum_{k=1}^{\infty}(3 k-1)^{2} P_{p}(3 k-1)+\frac{2}{3} \frac{1}{9} \sum_{k=1}^{\infty}(6 k-1) P_{p}(3 k-1) \\
& +\frac{1}{9} \sum_{k=1}^{\infty}(3 k)^{2} P_{p}(3 k)+\frac{2}{3} \frac{1}{9} \sum_{k=1}^{\infty}(3 k+1)^{2} P_{p}(3 k+1) \\
& +\frac{2}{3} \frac{1}{9} \sum_{k=1}^{\infty}(-6 k-1) P_{p}(3 k+1)+\frac{1}{3} \frac{1}{9} \sum_{k=1}^{\infty}(3 k+2)^{2} P_{p}(3 k+2) \\
& +\frac{1}{3} \frac{1}{9} \sum_{k=1}^{\infty}(-12 k-4) P_{p}(3 k+2) \\
& =\frac{1}{9} \sum_{k=1}^{\infty} k^{2} P_{p}(k)+\frac{2}{9}\left[\sum_{k=1}^{\infty} P_{p}(3 k-1)+\sum_{k=1}^{\infty} P_{p}(3 k-2)\right]
\end{aligned}
$$




$$
\begin{gathered}
\text { Since } \sum_{k=1}^{\infty} P_{p}(3 k-1)+\sum_{k=1}^{\infty} P_{p}(3 k-2)=1-\sum_{k=0}^{\infty} P_{p}(3 k) \text {, one has } \\
E\left(k^{2} \mid \lambda\right)=\frac{1}{9} \sum_{k=1}^{\infty} k^{2} P_{p}(k)+\frac{2}{9}\left[1-\sum_{k=0}^{\infty} P_{p}(3 k)\right] .
\end{gathered}
$$

The second moment about the origin of a random variable which has the Poisson distribution with parameter $\lambda$ is $\lambda+\lambda^{2}$. To compute $\sum_{k=0}^{\infty} P_{p}(3 k)$, note that $\sum_{k=0}^{\infty} \frac{\lambda^{3 k}}{(3 k) !}=\frac{I}{3}\left[\sum_{k=0}^{\infty} \frac{\lambda^{k}}{k !}+\sum_{k=0}^{\infty} \frac{(\omega \lambda)^{k}}{k !}+\sum_{k=0}^{\infty} \frac{\left(\omega^{2} \lambda\right)^{k}}{k !}\right]$

where $\omega=(-1+i \sqrt{ } 3) / 2$, $i$ being such that $i^{2}=\sqrt{ }-1$. Hence

$$
\begin{aligned}
& \sum_{k=0}^{\infty} \frac{\lambda^{3 k}}{(3 k) !}=\frac{1}{3}\left(e^{\lambda}+e^{\omega \lambda}+e^{\omega^{2} \lambda}\right)=\frac{1}{3}\left[e^{\lambda}+e^{-\lambda / 2}\left[\cos \left(\frac{\sqrt{3}}{2} \lambda\right)+i \sin \left(\frac{\sqrt{3}}{2} \lambda\right)\right]\right\} \\
& \left.+e^{-\lambda / 2}\left[\cos \left(\frac{\sqrt{3}}{2} \lambda\right)-i \sin \left(\frac{\sqrt{3}}{2} \lambda\right)\right]\right\}=\frac{1}{3}\left[e^{\lambda}+2 e^{-\lambda / 2} \cos \left(\frac{\sqrt{3}}{2} \lambda\right)\right] .
\end{aligned}
$$

Therefore

$$
\begin{aligned}
E\left(k^{2} \mid \lambda\right) & =\frac{1}{9}\left(\lambda+\lambda^{2}\right)+\frac{2}{9}\left\{1-\frac{1}{3}\left[1+2 e^{-\frac{3}{2} \lambda} \cos \left(\frac{\sqrt{ } 3}{2} \lambda\right)\right]\right\} \\
& =\frac{1}{9}\left(\lambda+\lambda^{2}\right)+\frac{4}{27}\left[1-e^{-\frac{3}{2} \lambda} \cos \left(\frac{\sqrt{3}}{2} \lambda\right)\right]
\end{aligned}
$$

Since $E(k \mid \lambda)=\frac{\lambda}{3}$, one obtains

$$
V(k \mid \lambda)=\frac{\lambda}{9}+\frac{4}{27}\left[1-e^{-\frac{3}{2} \lambda} \cos \left(\frac{\sqrt{3}}{2} \lambda\right)\right]
$$

The variability ratio $\mathrm{V}(\mathrm{k} \mid \lambda) / \mathrm{E}(\mathrm{k} \mid \lambda)=\frac{1}{3}+\frac{4}{9 \lambda}\left[1-e^{-\frac{3}{2} \lambda} \cos \left(\frac{\sqrt{3}}{2} \lambda\right)\right]$ goes to $\frac{1}{3}$ as $\lambda$ goes to infinity. 
20.

APPENDIX C

Correlation between Purchases in

Successive Periods for a Condensed-3 Poisson Distribution

Let $k_{1}$ be the number of purchases over Period 1 and $k_{2}$ be the number of purchases over Period 2. We have

$$
\mathrm{V}\left(\mathrm{k}_{1}+\mathrm{k}_{2}\right)=\mathrm{V}\left(\mathrm{k}_{1}\right)+\mathrm{V}\left(\mathrm{k}_{2}\right)+2 \operatorname{cov}\left(\mathrm{k}_{1}, \mathrm{k}_{2}\right)
$$

$k_{1}$ and $k_{2}$ follow a Condensed-3 Poisson distribution with parameter $\lambda / 3$.

Hence

$$
V\left(k_{1}\right)=V\left(k_{2}\right)=\frac{\lambda}{9}+\frac{4}{27}\left[1-e^{-\frac{3}{2} \lambda} \cos \left(\frac{\sqrt{3}}{2} \lambda\right)\right],
$$

and the sum $\left(k_{1}+k_{2}\right)$ follows a Condensed-3 Poisson distribution with

parameter $2 \lambda / 3$. Hence

$$
\mathrm{V}\left(\mathrm{k}_{1}+\mathrm{k}_{2}\right)=\frac{2}{9} \lambda+\frac{4}{27}\left[1-e^{-3 \lambda} \cos (\sqrt{3} \lambda)\right]
$$

Therefore

$$
\operatorname{cov}\left(k_{1}, k_{2}\right)=\frac{2}{27}\left[2 e^{-\frac{3}{2} \lambda} \cos \left(\frac{\sqrt{3}}{2} \lambda\right)-e^{-3 \lambda} \cos (\sqrt{3} \lambda)-1\right] .
$$

The correlation between $k_{1}$ and $k_{2}, \rho_{12}$, is equal to

$\rho_{12}=\left[2 e^{-\frac{3}{2} \lambda} \cos \left(\frac{\sqrt{3}}{2} \lambda\right)-e^{-3 \lambda} \cos (\sqrt{3} \lambda)-1\right] /\left[-2 e^{-\frac{3}{2} \lambda} \cos \left(\frac{\sqrt{3}}{2} \lambda\right)+\frac{3}{2} \lambda+2\right]$. 
As $\lambda \rightarrow 0, \rho_{12} \rightarrow 0$, and as $\lambda \rightarrow+\infty, p_{12} \rightarrow 0$. For $\lambda>0, p_{12}$ is

negative. Its maximum in absolute value $\rho_{12} \approx-.226$ is attained when $\lambda \approx 1.276$ (IMSL 1979a). 
Variance of the Condensed-3 Negative Binomial Distribution

From the conditional mean and variance of $k$, we derive the unconditional variance of $k$ (Rao 1973, p. 97)

$$
V(k)=\underset{\lambda}{V}[E(k \mid \lambda)]+\underset{\lambda}{E}[V(k \mid \lambda)]
$$

where $\lambda$ follows a gamma distribution with shape parameter $r$ and scale parameter $3 \sigma$ over the population. Therefore

$$
V(k)=\underset{\lambda}{V}\left(\frac{\lambda}{3}\right)+\underset{\lambda}{E}\left\{\frac{\lambda}{9}+\frac{4}{27}\left[1-e^{-\frac{3}{2} \lambda} \cdot \cos \left(\frac{\sqrt{3}}{2} \lambda\right)\right]\right\}
$$

Since $\quad \underset{\lambda}{V}\left(\frac{\lambda}{3}\right)=\frac{1}{9} 9 \sigma^{2} r=\sigma^{2} r$ and $\frac{E}{\lambda}\left(\frac{\lambda}{9}\right)=\frac{1}{9} 3 \sigma r=\frac{\sigma r}{3}$, one has

$$
\begin{aligned}
& V(k)=\sigma^{2} r+\frac{\sigma r}{3}+\frac{4}{27} E\left[1-e^{-\frac{3}{2} \lambda} \cos \left(\frac{\sqrt{3}}{2} \lambda\right)\right] \text {. Since } f(\lambda \mid r, \sigma)=\frac{1}{(3 \sigma)^{r}} \Gamma(r) \\
& \lambda^{r-1} e^{-\frac{\lambda}{3 \sigma}}, E\left[e^{-\frac{3}{2} \lambda} \cos \left(\frac{\sqrt{3}}{2} \lambda\right)\right]=\int_{0}^{+\infty} e^{-\frac{3}{2} \lambda} \cos \left(\frac{\sqrt{3}}{2} \lambda\right) \cdot \frac{1}{(3 \sigma)^{r}} \Gamma(r) \\
& \lambda^{r-1} e^{-\frac{\lambda}{3 \sigma}} d \lambda
\end{aligned}
$$

$$
=\frac{1}{(3 \sigma)^{r} \Gamma(r)} \int_{0}^{+\infty} \cos \left(\frac{v^{\prime} 3}{2} \lambda\right) \lambda^{r-1} e^{-\left(\frac{3}{2}+\frac{1}{3 \sigma}\right) \lambda} d \lambda=\frac{1}{(3 \sigma)^{r} \Gamma(r)} \frac{\Gamma(r) \cos (r \delta)}{\left[\left(\frac{3}{2}+\frac{1}{3 \sigma}\right)^{2}+\frac{3}{4}\right]^{1}}
$$$$
=\frac{\cos (r \delta)}{(3 \sigma)^{r}\left[\left(\frac{3}{2}+\frac{1}{3 \sigma}\right)^{2}+\frac{3}{4}\right]^{r / 2}} \text { where sino }=\frac{\sqrt{ } 3}{2 q}, \cos \delta=\frac{1}{q}\left(\frac{3}{2}+\frac{1}{3 \sigma}\right) \text { and }
$$ 


$$
\begin{gathered}
q=\left[\left(\frac{3}{2}+\frac{1}{3 \sigma}\right)^{2}+\frac{3}{4}\right]^{\frac{1}{2}} \text {. After some simplifications, we obtain } \\
V(k)=\text { or }\left(\sigma+\frac{1}{3}\right)+\frac{4}{27}\left\{1-\frac{\cos (r \delta)}{\left(1+9 \sigma+27 \sigma^{2}\right)^{r / 2}}\right\} .
\end{gathered}
$$


Brand Purchase Distribution when the Purchase Timing Model is the Negative Binomial Distribution and the Brand Choice Mode1 is the Beta Binomial Distribution

Consider the Poisson distribution of $\mathrm{x}$ given in (6). Under the assumptions $A 1, A 2$ and $A 3$, the distribution of $x$, unconditioned on $\theta_{i}$ and $\lambda$, is

$$
\begin{aligned}
P(x) & =\int_{0}^{1} \int_{0}^{+\infty} e^{-\lambda \theta_{i}} \frac{\left(\lambda \theta_{i}\right)^{x}}{x !} \frac{\Gamma(c)}{\Gamma\left(a_{i}\right) \Gamma\left(b_{i}\right)} \theta_{i}^{a_{i}^{-1}}\left(1-\theta_{i}\right)^{b_{i}-1} \frac{1}{\Gamma(r) \sigma^{r}} \lambda^{r-1} e^{-\frac{1}{\sigma} \lambda} d \lambda d \theta_{i} \\
& =\frac{\Gamma(c) \sigma^{x} \Gamma(x+r)}{\Gamma\left(a_{i}\right) \Gamma\left(b_{i}\right) \Gamma(r) x !} \int_{0}^{1} \theta_{i}^{x+a_{i}-1}\left(1-\theta_{i}\right)^{b_{i}^{-1}}\left(1+\sigma \theta_{i}\right)^{-(x+r)} d \theta_{i} \cdot(E .1)
\end{aligned}
$$

The right-hand side of (E.1) includes the integral representation of a Lauricella series and can be expressed as

$$
P(x)=\frac{\Gamma(c) \sigma^{x} \Gamma(x+r) \Gamma\left(x+a_{i}\right)}{\Gamma\left(a_{i}\right) \Gamma(r) x ! \Gamma(x+c)} F_{D}^{(1)}\left(x+r, x+a_{i} ; x+c ;-\sigma\right)
$$


where $\mathrm{F}_{\mathrm{D}}^{(1)}(\cdot, \cdot ; \cdot ; \cdot)$ has the following general form (Exton 1976, p. 49)

$$
\begin{aligned}
& F_{D}^{(p)}\left(m_{0}, s_{1}, \ldots, s_{p} ; u ; z_{1}, \ldots, z_{p}\right)=\frac{\Gamma(u)}{\Gamma\left(m_{0}\right) \Gamma\left(u-m_{0}\right)} \int_{0}^{1} w^{m_{0}-1}(1-w){ }^{u-m_{0}-1} \\
& \left(1-z_{1} w\right)^{-s_{1}} \ldots\left(1-z_{p} w\right)^{-s_{p}} d w
\end{aligned}
$$

with $u>u-m_{0}>0$ and $\left|z_{i}\right|<1 \quad(i=1, \ldots, p)$ for absolute convergence. For $x=0,(E .2)$ becomes

$$
P(0)=F_{D}^{(1)}\left(r, a_{i} ; c ;-\sigma\right)
$$


Penetration of a Brand when the Purchase Timing Mode1 is a Condensed Negative Binomial Distribution and the Brand Choice Model is a Beta Binomial Distribution

Assume that $\mathrm{P}(\mathrm{k} \mid \lambda)$ in (5) is a Condensed-2 Poisson distribution as given in (7). For $x=0,(5)$ becomes

$$
\begin{aligned}
& P\left(x=0 \mid \theta_{i}, \lambda\right)=P_{p}(0)+\frac{1}{2} P_{p}(1)+\frac{1}{2} \sum_{k=1}^{\infty}\left(1-\theta_{i}\right)^{k} P_{p}(2 k-1) \\
& +\sum_{k=1}^{\infty}\left(1-\theta_{i}\right)^{k} P_{p}(2 k)+\frac{1}{2} \sum_{k=1}^{\infty}\left(1-\theta_{i}\right)^{k} P_{p}(2 k+1) \cdot \quad(F .1) \\
& \text { Let } \xi \doteq\left(1-\theta_{i}\right)^{\frac{1}{2}} \text {. Then } \\
& \sum_{k=1}^{\infty}\left(1-\theta_{i}\right)^{k} P_{p}(2 k-1)=\xi e^{-\lambda} \sum_{k=1}^{\infty} \frac{(\xi \lambda)^{2 k-1}}{(2 k-1) !}=\xi e^{-\lambda} \sinh (\xi \lambda) \\
& \sum_{k=1}^{\infty}\left(1-\theta_{i}\right)^{k} P_{p}(2 k)=e^{-\lambda} \sum_{k=1}^{\infty} \frac{(\xi \lambda)^{2 k}}{(2 k) !}=e^{-\lambda}[\cosh (\xi \lambda)-1]
\end{aligned}
$$


and

$$
\sum_{k=1}^{\infty}\left(1-\theta_{i}\right)^{k} P_{p}(2 k+1)=\xi^{-1} e^{-\lambda} \sum_{k=1}^{\infty} \frac{(\xi \lambda)^{2 k+1}}{(2 k+1) !}=\xi^{-1} e^{-\lambda}[\sinh (\xi \lambda)-\lambda] .
$$

Using these last three expressions, we find

$$
P\left(x=0 \mid \theta_{i}, \lambda\right)=e^{-\lambda}\left[\frac{1}{2} \xi \sinh (\xi \lambda)+\cosh (\xi \lambda)+\frac{1}{2} \xi^{-1} \sinh (\xi \lambda)\right]
$$

Assume that $\mathrm{A} 1, \mathrm{~A} 2$ and $\mathrm{A} 3$ are met. After a change of variable $v=\left(1-\theta_{i}\right)^{\frac{1}{2}}$ is made, the unconditioned probability of no purchase is given by

$$
\begin{aligned}
& P(x=0)=\frac{\Gamma(c) \Gamma\left(2 b_{i}-1\right)}{\Gamma\left(b_{i}\right) \Gamma\left(a_{i}+2 b_{i}-1\right)}(1+2 \sigma)-r\left\{\frac{1}{2} \frac{\left(2 b_{i}-1\right) 2 b_{i}}{\left(a_{i}+2 b_{i}-1\right)\left(a+2 b_{i}\right)}\right. \\
& {\left[F_{D}^{(2)}\left(2 b_{i}+1,-a_{i}+1, r ; a_{i}+2 b_{i}+1 ;-1, \frac{-2 \sigma}{1+2 \sigma}\right)\right.} \\
& \left.-F_{D}^{(2)}\left(2 b_{i}+1,-a_{i}+1, r ; a_{i}+2 b_{i}+1 ;-1, \frac{2 \sigma}{1+2 \sigma}\right)\right] \\
& +\frac{\left(2 b_{i}-1\right)}{\left(a_{i}+2 b_{i}^{-1)}\right.}\left[F_{D}^{(2)}\left(2 b_{i},-a_{i}+1, r ; a_{i}+2 b i-1, \frac{-2 \sigma}{1+2 \sigma}\right)\right. \\
& \left.-F_{D}^{(2)}\left(2 b_{i},-a_{i}+1, r ; a_{i}+2 b_{i} ;-1, \frac{2 \sigma}{1+2 \sigma}\right)\right] \\
& +\frac{1}{2}\left[F_{D}^{(2)}\left(2 b_{i}-1,-a_{i}+1, r ; a_{i}+2 b_{i}-1 ;-1, \frac{-2 \sigma}{1+2 \sigma}\right)\right.
\end{aligned}
$$




$$
\left.\left.-\mathrm{F}_{\mathrm{D}}^{(2)}\left(2 \mathrm{~b}_{i}-1,-\mathrm{a}_{i}+1, \mathrm{r} ; \mathrm{a}_{i}+2 \mathrm{~b}_{i}-1 ;-1, \frac{2 \sigma}{1+2 \sigma}\right)\right]\right\}
$$

where $F_{D}^{(2)}(., \ldots, ., ; . ; .,$.$) is the integral representation of a Lauricella$ series.

Assume that $\mathrm{P}(\mathrm{k} \mid \lambda)$ in (5) is a Condensed-3 Poisson distribution defined in (2). Then (5) becomes

$$
\begin{aligned}
P\left(x=0 \mid \theta_{i}, \lambda\right) & =P_{p}(0)+\frac{2}{3} P_{p}(1)+\frac{1}{3} P_{p}(2)+\frac{1}{3} \sum_{k=1}^{\infty}\left(1-\theta_{i}\right)^{k} P_{p}(3 k-2) \\
& +\frac{2}{3} \sum_{k=1}^{\infty}\left(1-\theta_{i}\right)^{k} P_{p}(3 k-1)+\sum_{k=1}^{\infty}\left(1-\theta_{i}\right)^{k} P_{p}(3 k) \\
& +\frac{2}{3} \sum_{k=1}^{\infty}\left(1-\theta_{i}\right)^{k} P_{p}(3 k+1)+\frac{1}{3} \sum_{k=1}^{\infty}\left(1-\theta_{i}\right)^{k} P_{P}(3 k+2) .
\end{aligned}
$$

Let $\xi=\left(1-\theta_{i}\right)^{\frac{1}{3}}$. From (B.1), we derive the following expressions

$$
\begin{aligned}
& \sum_{k=1}^{\infty}\left(1-\theta_{i}\right)^{k} P_{p}(3 k-2)=\frac{1}{3} \xi^{2} e^{-\lambda}\left[e^{\xi \lambda}-e^{-\xi \lambda / 2}\left(\cos \left(\frac{\sqrt{ } 3}{2} \xi \lambda\right)-\sqrt{3} \sin \left(\frac{\sqrt{ } 3}{2} \xi \lambda\right)\right)\right] \\
& \sum_{k=1}^{\infty}\left(1-\theta_{i}\right)^{k} P_{p}(3 k-1)=\frac{1}{3} \xi e^{-\lambda}\left[e^{\cdot \xi \lambda}-e^{-\xi \lambda / 2}\left(\cos \left(\frac{\sqrt{3}}{2} \xi \lambda\right)+\sqrt{3} \sin \left(\frac{\sqrt{3}}{2} \xi \lambda\right)\right)\right] \\
& \sum_{k=1}^{\infty}\left(1-\theta_{i}\right)^{k} P_{p}(3 k)=e^{-\lambda}\left\{\frac{1}{3}\left[e^{\xi \lambda}+2 e^{-\xi \lambda / 2} \cos \left(\frac{\sqrt{3}}{2} \xi \lambda\right)\right]-1\right\}, \\
& \sum_{k=1}^{\infty}\left(1-\theta_{i}\right)^{k} P_{p}(3 k+1)=\xi^{-1} e^{-\lambda}\left\{\frac { 1 } { 3 } \left[e^{\xi \lambda}-e^{-\xi \lambda / 2}\left(\cos \left(\frac{\sqrt{3}}{2} \xi \lambda\right)\right.\right.\right. \\
& \left.\left.\left.-\sqrt{3} \sin \left(\frac{\sqrt{3}}{2} \xi \lambda\right)\right)\right]-\xi \lambda\right\} \\
& \sum_{k=1}^{\infty}\left(1-\theta_{i}\right)^{k} P_{p}(3 k+2)=\xi^{-2} e^{-\lambda}\left\{\frac { 1 } { 3 } \left[e^{\xi \lambda}-e^{-\xi \lambda / 2}\left(\cos \left(\frac{\sqrt{3}}{2} \xi \lambda\right)\right.\right.\right. \\
& \left.\left.+\sqrt{3} \sin \left(\frac{\sqrt{3}}{2} \xi \lambda\right)\right)\right]-\frac{(\xi \lambda)^{2}}{2 !} .
\end{aligned}
$$


Using these five expressions, we find

$$
\begin{aligned}
\mathrm{P}\left(\mathrm{x}=0 \mid \theta_{i}, \lambda\right) & =\frac{1}{3} e^{-\lambda}\left[\mathrm{e}^{\xi \lambda}\left(\frac{1}{3} \xi^{2}+\frac{2}{3} \xi+1+\frac{2}{3} \xi^{-1}+\frac{1}{3} \xi^{-2}\right)\right. \\
& =e^{-\xi \lambda / 2} \cos \left(\frac{\sqrt{3}}{2} \xi \lambda\right)\left(\frac{1}{3} \xi^{2}+\frac{2}{3} \xi-2+\frac{2}{3} \xi^{-1}+\frac{1}{3} \xi^{-2}\right) \\
& \left.+\frac{\sqrt{3}}{3} e^{-\xi \lambda / 2} \sin \left(\frac{\sqrt{3}}{2} \xi \lambda\right)\left(\xi^{2}-2 \xi+2 \xi^{-1}-\xi^{-2}\right)\right] .
\end{aligned}
$$

Under the assumptions Al, A2 and A3 and after a change of variable $v=\left(1-\theta_{i}\right)^{\frac{1}{3}}$ is made, the unconditional probability of no purchase is given by

$$
P(x=0)=\frac{\Gamma(c) \Gamma\left(3 b_{i}-2\right)}{\Gamma\left(3 b_{i}\right) \Gamma\left(a_{i}+3 b_{i}-2\right)}(1+3 \sigma)^{-r}\left\{\frac{1}{3} \frac{\left(3 b_{i}-2\right)\left(3 b_{i}-1\right) 3 b_{i}\left(3 b_{i}+1\right)}{\left(a_{i}+3 b_{i}-2\right)\left(a_{i}+3 b_{i}-1\right)\left(a_{i}+3 b_{i}\right)\left(a_{i}+3 b_{i}+1\right)}\right.
$$

$$
\left[G\left(\left(3 b_{i}+2, a_{i}+2, a_{i}+3 b_{i}+2\right)\right)-\sqrt{3} H\left(\left(3 b_{i}+2, a_{i}+3 b_{i}+2\right)\right)\right.
$$$$
\left.-F_{D}^{(4)}\left(\left(3 b_{i}+2, a_{i}+3 b_{i}+2\right)\right)\right]+\frac{2}{3} \frac{\left(3 b_{i}-2\right)\left(3 b_{i}-1\right) 3 b_{i}}{\left(a_{i}+3 b_{i}-2\right)\left(a_{i}+3 b_{i}-1\right)\left(a_{i}+3 b_{i}\right)}
$$$$
\left[G\left(\left(3 b_{i}+1, a_{i}+3 b_{i}+1\right)\right)+\sqrt{3} H\left(\left(3 b_{i}+1, a_{i}+3 b_{i}+1\right)\right)\right.
$$$$
\left.-F_{D}^{(4)}\left(\left(3 b_{i}+1, a_{i}+3 b_{i}+1\right)\right)\right]-\frac{\left(3 b_{i}-2\right)\left(3 b_{i}-1\right)}{\left(a_{i}+3 b_{i}-2\right)\left(a_{i}+3 b_{i}-1\right)}
$$

$\left[2 G\left(\left(3 b_{i}, a_{i}+3 b_{i}\right)\right)+F_{D}^{(4)}\left(\left(3 b_{i}, a_{i}+3 b_{i}\right)\right)\right]$

$$
+\frac{2}{3} \frac{\left(3 b_{i}-2\right)}{\left(a_{i}+3 b_{i}-2\right)}\left[G\left(\left(3 b_{i}-1, a_{i}+3 b_{i}-1\right)\right)-\sqrt{3} H\left(\left(3 b_{i}-1, a_{i}+3 b_{i}-1\right)\right)\right.
$$


30.

$\left.-F_{D}^{(4)}\left(\left(3 b_{i}-1, a_{i}+3 b_{i}-1\right)\right)\right]+\frac{1}{3}\left[G\left(\left(3 b_{i}-2, a_{i}+3 b_{i}-2\right)\right)\right.$

$\left.\left.-\sqrt{3} H\left(\left(3 b_{i}-2, a_{i}+3 b_{i}-2\right)\right)-F_{D}^{(4)}\left(\left(3 b_{i}-2, a_{i}+3 b_{i}-2\right)\right)\right]\right\}$

where $F_{D}^{(4)}\left(\left(m_{0}, u\right)\right)$ is a concise fashion of writing

$\mathrm{F}_{\mathrm{D}}^{(4)}\left(\mathrm{m}_{\mathrm{O}},-\mathrm{a}_{i}+1,-\mathrm{a}_{i}+1, \mathrm{r} / 2 ; \mathrm{u} ;-\frac{1}{2}-i \frac{\sqrt{ } 3}{2},-\frac{1}{2}+i \frac{\sqrt{ } 3}{2},-\frac{1}{2} \frac{3 \sigma}{1+3 \sigma}\right.$

- i $\left.\frac{\sqrt{3}}{2} \frac{3 \sigma}{1+3 \sigma},-\frac{1}{2} \frac{3 \sigma}{1+3 \sigma}+i \frac{\sqrt{3}}{2} \frac{3 \sigma}{1+3 \sigma}\right) \cdot G\left[\left(\mathrm{n}_{0}, \mathrm{v}\right)\right]$ and $\mathrm{H}\left[\left(\mathrm{n}_{0}, \mathrm{v}\right)\right]$ are

short-cut representations of the following integrals

$$
\begin{aligned}
& G\left[\left(n_{0}, v\right)\right]=\frac{\Gamma(v)}{\Gamma\left(n_{0}\right) \Gamma\left(v-n_{0}\right)} \cdot \int_{0}^{1} \cos (r \delta) w^{n_{0}-1}(1-w)^{v-n_{0}-1}\left[1+\left(\frac{1}{2}+i \frac{\sqrt{3}}{2}\right) w\right] w^{v-n_{0}-1} \\
& {\left[1+\left(\frac{1}{2}-i \frac{\sqrt{3}}{2}\right) w\right]^{v-n_{0}^{-1}}\left[1+\left(\frac{1}{2} \frac{3 \sigma}{1+3 \sigma}+i \frac{\sqrt{3}}{2} \frac{3 \sigma}{1+3 \sigma}\right) w\right]^{-r / 2}\left[1+\left(\frac{1}{2} \frac{3 \sigma}{1+3 \sigma}\right.\right.} \\
& \left.\left.-i \frac{\sqrt{3}}{2} \frac{3 \sigma}{1+3 \sigma}\right) w\right]^{-r / 2} d w
\end{aligned}
$$

and

$$
\begin{aligned}
& H\left[\left(n_{0}, v\right)\right]=\frac{\Gamma(v)}{\Gamma\left(n_{0}\right) \Gamma\left(v-n_{0}\right)} \int_{0}^{1} \sin (r \delta) w^{n_{0}-1}(1-w)^{v-n_{0}-1} \\
& {\left[1+\left(\frac{1}{2}+i \frac{\sqrt{3}}{2}\right) w\right]^{\mathrm{v}-\mathrm{n}_{0}-1}\left[1+\left(\frac{1}{2}-i \frac{\sqrt{3}}{2}\right) \mathrm{w}\right]^{\mathrm{v}-\mathrm{n}_{0}} \mathrm{O}^{-1}} \\
& {\left[1+\left(\frac{1}{2} \frac{3 \sigma}{1+3 \sigma}+i \frac{\sqrt{3}}{2} \frac{3 \sigma}{1+3 \sigma}\right) w\right]^{-r / 2}\left[1+\left(\frac{1}{2} \frac{3 \sigma}{1+3 \sigma}-i \frac{\sqrt{3}}{2} \frac{3 \sigma}{1+3 \sigma}\right) w\right]^{-r / 2} d w}
\end{aligned}
$$

with $\sin \delta=\frac{\sqrt{3}}{2} \mathrm{w} / \mathrm{q}, \cos \delta=\left(\frac{1+3 \sigma}{3 \sigma}+\frac{1}{2} \mathrm{w}\right) / \mathrm{q}$ and $\mathrm{q}=\left[\left(\frac{1+3 \sigma}{3 \sigma}\right)^{2}+\left(\frac{1+3 \sigma}{3 \sigma}\right) \mathrm{w}^{2} \mathrm{w}^{2}\right]^{1 / 2}$. 
APPENDIX G

Mean and Variance of the Brand Purchase Distribution

The conditional mean and variance of (6) are

$$
\begin{aligned}
& \mathrm{E}\left(\mathrm{x} \mid \theta_{i}, \lambda\right)=\lambda \theta_{i} \\
& \mathrm{~V}\left(\mathrm{x} \mid \theta_{i}, \lambda\right)=\lambda \theta_{i} .
\end{aligned}
$$

Under the assumption $A 1$, the unconditional mean of $x$ is

$$
E(x)=\begin{array}{cc}
E & E\left[E\left(x \mid \theta_{i}, \lambda\right)\right]=E(\lambda) E\left(\theta_{i}\right) \\
\theta_{i} & \lambda
\end{array}
$$

and the unconditional variance of $x$ is

$$
\begin{aligned}
& V(x)=\underset{\theta_{i}}{E}\left[V\left(x \mid \theta_{i}\right)\right]+\underset{\theta_{i}}{V}\left[E\left(x \mid \theta_{i}\right)\right]
\end{aligned}
$$

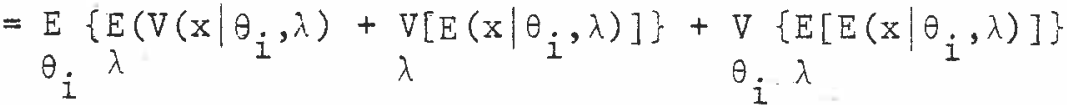

$$
\begin{aligned}
& =\underset{\theta_{i}}{E}\left[\theta_{i} E(\lambda)+\theta_{i}^{2} V(\lambda)\right]+\underset{\theta_{i}}{V}\left[\theta_{i} E(\lambda)\right] \\
& =E(\lambda) E\left(\theta_{i}\right)+V(\lambda) E\left(\theta_{i}{ }^{2}\right)+E(\lambda)^{2} V\left(\theta_{i}\right) .
\end{aligned}
$$

Assume that A2 and A3 are met. (G.1) becomes

$$
E(x)=\frac{r \sigma a_{i}}{c}
$$

and (G.2) becomes

$$
V(x)=\frac{r \sigma a_{i}}{c}\left[\frac{\sigma}{c+1}\left(\frac{r b_{i}}{c}+a_{i}+1\right)+1\right] .
$$

Assume that $k$ follows a Condensed-2 Poisson distribution with parameter $\lambda$ with the following mean and variance 


$$
E(k \mid \lambda)=\frac{\lambda}{2}
$$

and

$$
V(k \mid \lambda)=\frac{\lambda}{4}+\frac{1}{4} e^{-\lambda} \sinh \lambda
$$

Using the same procedure as above, we find the following conditional mean and variance of $x$

$$
E\left(x \mid \theta_{i}, \dot{\lambda}\right)=\frac{\lambda \theta_{i}}{2}
$$

and

$$
V\left(x \mid \theta_{i}, \lambda\right)=\frac{\theta_{i}}{2}\left[\lambda-\frac{{ }^{\theta}}{2}\left(\lambda-e^{-\lambda} \sinh \lambda\right)\right] .
$$

Note that $\mathrm{x}$ does not follow a Condensed-2 Poisson distribution. Under the assumptions. $\mathrm{A}, \mathrm{A} 2$ and $\mathrm{A} 3$, it can be shown that the unconditional mean and variance of $\mathrm{x}$ are

$$
E(x)=\frac{r \sigma a_{i}}{c}
$$

and

$$
\begin{aligned}
V(x) & =\frac{r \sigma a_{i}}{c}\left[\frac{\sigma}{c+1}\left(\frac{r b_{i}}{c}+a_{i}+1\right)+1-\frac{a_{i}+1}{2(c+1)}\right] \\
& +\frac{1}{8} \frac{a_{i}\left(a_{i}+1\right)}{c(c+1)}\left[1-(1+4 \sigma)^{-r}\right] .
\end{aligned}
$$

Assume that $k$ follows a Condensed-3 Poisson distribution with parameter $\lambda$. The conditional mean of $k$ is $\lambda / 3$ and its conditional variance is given in $(B, 2)$. The conditional mean and variance of $x$ are given by

$$
E\left(x \mid \theta_{i}, \lambda\right)=\frac{\lambda \theta_{i}}{3}
$$

and

$$
V\left(x \mid \theta_{i}, \lambda\right)=\frac{\theta^{\theta}}{-3}\left\{\frac{2 \theta}{3}\left[\frac{2}{3}\left(1-e^{-\frac{3}{2} \lambda} \cos \left(\frac{\sqrt{3}}{2} \lambda\right)\right)-\lambda\right]+\lambda\right\} .
$$


Under the assumptions $\mathrm{A} 1, \mathrm{~A} 2$ and $\mathrm{A} 3$, the unconditional mean and variance of $\mathrm{x}$ are given by

$$
E(x)=\frac{r \sigma a_{i}}{c}
$$

and

$V(x)=\frac{r \sigma a_{i}}{c}\left[\frac{\sigma}{c+1}\left(\frac{r b_{i}}{c}+a_{i}+1\right)+1-\frac{2}{3} \frac{a_{i}+1}{c+1}\right]+\frac{4}{27} \frac{a_{i}\left(a_{i}+1\right)}{c(c+1)}\left[1-\frac{\cos (r \delta)}{\left(1+9 \sigma+27 \sigma^{2}\right)^{r / 2}}\right] / G .12$ with $\sin \delta=\frac{\sqrt{3}}{2 q}, \cos \delta=\frac{1}{q}\left(\frac{3}{2}+\frac{1}{3 \sigma}\right)$ and $q=\frac{1}{3 \sigma}\left(1+9 \sigma+27 \sigma^{2}\right)^{1 / 2}$. 
REFERENCES

Abramowitz, M., and Stegun, I.A. (eds.) (1964) Handbook of Mathematical

Functions, National Bureau of Standards, Applied Mathematics

Series 55, U.S. Government Printing Office, Washington, D.C. Banerjee, A.K., and Bhattacharyya, G.K. (1976) A Purchase Incidence

Mode1 with Inverse Gaussian Interpurchase Times, Journal of the American Statistical Association, 71 (December), 823-829. Barndorff-Nielsen, O., Blaesild, P., and Halgreen, C., (1978) First Hitting Time Models for the Generalized Inverse Gaussian Distribution, Stochastic Processes and Their Applications, 7 (March), 49-54. Bass, F.M., Jeuland, A.P., and Wright, G.P. (1976) Equilibrium Stochastic Choice and Market Penetration Theories: Derivations and Comparisons, Management Science, 22 (June), 1051-1063. Bemmaor, A.C. (1978) An Empirical Study of the Temporal Aggregation Bias in Stochastic Models of Brand Choice, 1978 Proceedings of the Business and Economic Statistics Section, American Statistical Association, 842-45. Chatfield, C., and Goodhardt, G. (1975) Results Concerning Brand Choice, Journal of Marketing Research, 12 (February), 110-113. Chatfield, C., and Goodhardt, G. (1973) A Consumer Purchasing Mode1 with Erlang Interpurchase Times, Journal of the American Statistical Association, 68 (December), 828-835. 
Cox, D.R., and Lewis, P.A.W. (1966) The Statistical Analysis of Series of Events, London: Methuen and Co., Ltd.

Dodson, J.A. (1976) An Information Measure for Determining the Order of Individual Brand Choice Processes, 1976 Proceedings of the Business and Economic Statistics Section, 69-72.

Ehrenberg, A.S.C. (1959) The Pattern of Consumer Purchases, Applied Statistics, $8,26-41$.

Exton, H. (1976) Multiple Hypergeometric Functions and Applications, Chichester, England: Ellis Horwood Limited.

Feller, W. (1968) An Introduction to Probability Theory and its Applications, vol. 1, Third Edition, New York, New York: John Wiley and Sons, Inc.

Haight, F.A. (1967) Handbook of the Poisson Distribution, London: John Wiley and Sons, Inc.

Hastings, N.A.J., and Peacock, J.B. (1974) Statistical Distributions: A Handbook for Students and Practitioners, London: Butterworth and Co., Ltd.

Herniter, J.D. (1971) A Probabilistic Market Model of Purchase Timing and Brand Selection, Management Science, 18, Part II (December), $102-113$.

International Mathematical Statistical Libraries, Inc. (IMSL 1979a), ZXMIN: A Quasi-Newton Algorithm for Finding the Minimum of a Function of N Variables. IMSL LIB-0007 Reference Manual, Houston, Texas. Revised, January 1979.

International Mathematical Statistical Libraries, Inc. (IMSL 1979b), DCADRE: Numerical Integration of a Function Using Cautious Adaptive Romberg Extrapolations. IMSL LIB-0007 Reference Manual, Houston, Texas. Revised, January 1979. 
Jeuland, A.P., Bass, F.M., and Wright, G.P. (1980) A Multibrand Stochastic Model Compounding Heterogeneous Erlang Timing and Multinomial Choice Processes, Operations Research, 28 (MarchApri1), 255-277.

Jones, J.M., and Zufryden, F.S. (1980) Adding Explanatory Variables to a Consumer Purchase Behavior Model: An Exploratory Study, Journal of Marketing Research, 17 (August), 323-34.

Kalwani, M.U., and Morrison, D.G. (1977) A Parsimonious Description of the Hendry System, Management Science, 23 (January), 467-477.

Massy, W.F. (1966) Order and Homogeneity of Family Specific Brand Switching Processes, Journal of Marketing Research, 3 (February), 48-54.

Mosimann, J.E. (1962) On the Compound Multinomial Distribution, the Multivariate $\beta$-Distribution, and Correlations among Proportions, Biometrika, $49,65-82$.

Rao, C.R. (1973) Linear Statistical Inference and Its Applications, Second Edition, New York, New York: John Wiley and Sons.

Shoemaker, R.W., Staelin, R., Kadane, J.B., and Shoaf, F.R. (1977)

Relation of Brand Choice to Purchase Frequency, Journal of Marketing Research, 14 (November), 458-468.

Zufryden, F.S. (1977) A Composite Heterogeneous Model of Brand Choice and Purchase Timing Behavior, Management Science, 24 (October), $121-136$. 